\title{
A telephone survey to determine the experiences of children and their parents/carers, following the initiation of a new medicine
}

\author{
Jeff Aston, ${ }^{1}$ Keith A Wilson, ${ }^{2}$ Anthony Sinclair, ${ }^{1}$ David Terry ${ }^{2}$
}

${ }^{1}$ Pharmacy Department, Birmingham Children's Hospital NHS Foundation Trust, Birmingham, UK

${ }^{2}$ School of Life and Health Sciences, Aston University, Birmingham, UK

Correspondence to Jeff Aston, Pharmacy Department, Birmingham Children's Hospital NHS Foundation Trust, Steelhouse Lane, Birmingham B4 6NH, UK; jeff.aston@bch.nhs.uk

Received 23 February 2016 Revised 10 July 2016 Accepted 25 July 2016 Published Online First 19 August 2016

EAHP Statement 4: Clinical Pharmacy Services.EAHP Statement 5: Patient Safety and Quality Assurance.EAHP Statement 6: Education and Research
CrossMark

To cite: Aston J, Wilson KA, Sinclair A, et al. Eur I Hosp Pharm 2017:24:266-271.

\begin{abstract}
Objective To determine what issues are experienced during the first few weeks of therapy by patients, and their parents/carers, when a child/young person has been prescribed a new medicine.
\end{abstract}

Method One hundred patients aged $\leq 18$ years of age prescribed a new medicine for $\geq 6$ weeks were recruited from a single UK National Health Service specialist paediatric hospital outpatient pharmacy. Six weeks after the first dispensing of their new medicine the patient or their parent/carer received telephone follow-up by a researcher and verbally completed a questionnaire containing both open and closed questions. Patient or parent/carer experiences were identified and analysed using thematic analysis and descriptive statistics.

Results Eighty-six participants were available for telephone follow-up. Six (7\%) had not started their medicine. Paediatric patients and their parents/carers experienced a range of issues during the first few weeks after starting a new medicine. These included additional concerns/questions (24/80,30\%), administration issues $(21 / 80,26.3 \%)$, adverse effects $(29 / 80,36.3 \%)$ and obtaining repeat supplies (12/80, 15\%). The Morisky Medication Adherence Scale indicated that 34/78 (43.6\%) participants had a high adherence rating, 35/78 (44.9\%) medium and 9/78 (11.5\%) a low rating. Conclusions Paediatric patients and their parents/ carers experience a range of issues during the first few weeks after starting a new medicine. Further research is required to determine the type of interventions that may further support medicines use in this group of patients.

\section{INTRODUCTION}

People prescribed self-administered medicines typically take about half their doses. ${ }^{1}$ Efforts to assist patients with adherence might improve the benefits of prescribed medicines.

Medicines taking in children may be influenced by parents/carers beliefs about the condition, treatment regimen, child resistance, relationships within families, desire to preserve normal life and input from health professionals. ${ }^{2}$

A recent study of the experiences of medicine-related issues encountered by parents/carers of paediatric liver transplant patients found they reported problems obtaining their medicine, administering the medicines and side effects (including insufficient knowledge of side effect management). ${ }^{3}$

A review of the medical notes of 11-18 years old patients with juvenile arthritis found that despite the increasing complexity of drug regimens major gaps existed in the documentation of knowledge and skills relevant to the self-management of such regimens by patients. ${ }^{4}$

Barber et al, in a study of adult patients started on chronic medicines, found they quickly became non-adherent and identified a number of medicine-related problems and information needs. ${ }^{5}$ These included side effects, concerns about taking a new medicine, swallowing difficulties and remembering the regimen. In response to these issues the National Health Service funded New Medicines Service (NMS) was established in England in 2011. ${ }^{6}$ This is a medication review delivered through community pharmacists to support people with long-term conditions newly prescribed a medicine. The NMS improves adherence by $10 \%$ and increases the number of medicines problems identified and resolved. ${ }^{7}$ Improved medication adherence has been shown to improve disease outcomes in children with cystic fibrosis, ${ }^{8}$ asthma ${ }^{9}$ and renal disease. ${ }^{10}$ However, the NMS may not be available to children and cannot be undertaken with a parent/carer. ${ }^{6}$

The rationale of medication review could apply to children with chronic diseases. ${ }^{11}$ Issues such as polypharmacy, wastage and medicine-related problems are likely to be similar to those in adults. However, a literature review, using AMED, British Nursing Index, CINAHL, EMBASE, HMIC, MEDLINE, PsycINFO and Health Business Elite, did not identify any studies of medication review specific to children. Recently, the UK National Institute for Health and Care Excellence recommended further research concerning medication review in children, including minimising medicine-related problems. ${ }^{12}$ Other initiatives that may optimise medicines use include better partnerships with patients, telephone helplines, internet support websites and improving collaboration between healthcare professionals. ${ }^{13}$

The present study focused on the experiences of patients and their parents/carers during the first few weeks after a paediatric patient began taking a new medicine.

\section{Aim}

To determine what medicine-related issues are experienced during the first few weeks of therapy by patients, and their parents/carers, when a child/ young person has been prescribed a new medicine.

\section{METHODS}

\section{Setting}

The study was undertaken at a specialist UK paediatric hospital (34 specialties, 361 beds, >174000 outpatient visits per year). ${ }^{14}$ 


\section{Participant recruitment}

Potential participants were identified through presentation of a prescription to the outpatient pharmacy which met the study inclusion criteria. Consent and recruitment were undertaken by pharmacists based in the hospital's outpatient pharmacy while the participant waited for their prescription. Written consent was taken from the patient's parent/carer if the child was below 16 years or the patient if 16 years or older. An assent form was used for patients aged 12-15 years and was signed by the patient alongside the parent/carer consent form. Age-related participant information leaflets were provided. To minimise impact on service delivery a convenience sample of participants were recruited during the period February to July 2015. This study was exploratory and the authors considered a recruitment number of 100 participants would provide sufficient range of specialties and participants to identify important findings. There were no known published studies to guide recruitment numbers.

\section{Inclusion criteria}

Participant inclusion criteria were: ages $0-18$ years; prescribed a new medicine to be taken for 6 weeks or longer; access to a telephone for follow-up; not receiving medication for a life-limiting condition; could understand written and spoken English. The authors considered a period of 6 weeks to have provided the patient, and their parent/carer, sufficient experience of taking the new medicine prior to follow-up.

\section{Data collection}

Demographic information was recorded from the patient's prescription: medical/surgical clinic attended, age/gender of the patient, medicine prescribed and therapeutic indication.

A questionnaire containing both open and closed questions was used as the research instrument. This was completed by telephone with direct support from the lead study researcher. Cognisant testing of the questionnaire was assessed with a parent of a child taking long-term medicines and piloted with five participants. Six weeks following the dispensing of their new medicine participants received telephone follow-up by the study lead researcher. Participants were asked: whether they had researched further information about the new medicine themselves and why, any concerns/questions occurring over the previous 6 weeks, if they had experienced any problems taking/ administering the medicine, whether they had experienced adverse effects from their new medicine and any problems arranging repeat supplies. Participants' adherence was assessed using the Morisky Medication Adherence Scale (MMAS-8). ${ }^{15}$

Responses were transcribed in real time by the researcher during the interview.

\section{Data analysis}

Responses were analysed using thematic analysis. The responses were listed, grouped by similar/related theme and coded. Collated responses were analysed using NVivo V.10. Quantitative results were analysed using descriptive statistics using The Statistical Package for Social Sciences (SPSS) V.22.

\section{RESULTS}

\section{Demographic information}

One hundred participants were recruited to the study. Fifty-one patients were female and 49 male with a mean age of 8 years (range $0.33-17$ years). Patients were managed by one of 15 specialties (table 1).
In total 145 medicines were prescribed which patients had not previously received (table 2).

Eighty-six participants received telephone follow-up. Follow-up was undertaken with $83(96.5 \%)$ parents/carers and three $(3.5 \%)$ young people (two aged 16 years and one 14 years following parental consent). Fourteen participants were not contactable.

\section{Adherence to the prescribed regimen}

Telephone follow-up revealed that six (7\%) patients had not taken their medicine. Two parents/carers were concerned about side effects (macrogol and topical corticosteroid), two had not required their medicine (chlorphenamine, pizotifen and sumatriptan), one patient refused to be administered a macrogol suspension and one patient was concerned about how nifedipine would interact with her other medicines.

I read the leaflet that it came with then decided to try naturally. I haven't started her on it yet. They said that she wasn't drinking enough. I pushed the fluids, she's been better than she was. It can cause diarrhoea and I didn't want to send her the other way... Parent of Patient 18 (macrogol)

I haven't been taking it because I couldn't find out if it was compatible with my other medicines. I'm doing my exams at the moment, I didn't think it would be very smart to take them. Patient 46 (nifedipine)

The MMAS- 8 was used to determine self-reported adherence. Thirty-four (43.6\%) scored zero indicting high adherence, 35 (44.9\%) scored 1-2 indicating medium adherence and nine $(11.5 \%)$ had a score $>2$ indicating low adherence. Two participants were receiving medicine that was used on a 'when required' basis and thus were excluded from the analysis.

Four $(5 \%)$ participants had purchased medicine compliance aids.

We were advised to take it with or after food. If I'd forgotten I didn't know if I could then give it and so I would miss the dose and give his next one. Parent of Patient 61 (ursodeoxycholic acid)

I don't find it difficult to stick to the plan because I know we have to stick to it because it's for his eyes. A bit inconvenienced...it blows his weekend out. We give it on a Saturday morning so we can do something on a Friday night if we want

Table 1 Specialties

\begin{tabular}{lc}
\hline Specialty & N \\
\hline General paediatrics & 23 \\
Ear, nose and throat & 14 \\
Neurology & 13 \\
Dermatology & 10 \\
Urology & 9 \\
Respiratory & 7 \\
Rheumatology & 5 \\
Emergency department & 3 \\
Gastroenterology & 3 \\
Hepatology & 3 \\
Nephrology & 3 \\
Ophthalmology & 3 \\
Cardiology & 2 \\
Inherited metabolic diseases & 1 \\
Plastics & 1 \\
\hline
\end{tabular}


Table 2 Medicines prescribed for study participants

\begin{tabular}{|c|c|c|}
\hline Therapeutic use & $\begin{array}{l}\text { Number of } \\
\text { medicines (\%) }\end{array}$ & Medicine (n) \\
\hline Eczema & $27(18.6 \%)$ & $\begin{array}{l}\text { Topical corticosteroid (13) } \\
\text { Emollient (7) } \\
\text { Dressings (3) } \\
\text { Hydroxyzine (2) } \\
\text { Potassium permanganate (1) } \\
\text { Topical tacrolimus (1) }\end{array}$ \\
\hline Asthma & $17(11.7 \%)$ & $\begin{array}{l}\text { Beclometasone (6) } \\
\text { Montelukast (4) } \\
\text { Fluticasone (2) } \\
\text { Fluticasone/salmeterol (2) } \\
\text { Salbutamol (2) } \\
\text { Ipratropium (1) }\end{array}$ \\
\hline Allergy & $14(9.7 \%)$ & $\begin{array}{l}\text { Fluticasone (8) } \\
\text { Cetirizine (2) } \\
\text { Epinephrine (1) } \\
\text { Chlorphenamine (1) } \\
\text { Desloratadine (1) } \\
\text { Nutramigen (1) }\end{array}$ \\
\hline $\begin{array}{l}\text { Urinary frequencyl } \\
\text { enuresis }\end{array}$ & $14(9.7 \%)$ & $\begin{array}{l}\text { Desmopressin (6) } \\
\text { Oxybutynin (6) } \\
\text { Tolterodine (2) }\end{array}$ \\
\hline Migraine/headache & $11(7.6 \%)$ & $\begin{array}{l}\text { Pizotifen (6) } \\
\text { Propranolol (2) } \\
\text { Sumatriptan (2) } \\
\text { Migraleve (1) }\end{array}$ \\
\hline $\begin{array}{l}\text { Gastro-oesophageal } \\
\text { reflux }\end{array}$ & $9(6.2 \%)$ & $\begin{array}{l}\text { Ranitidine (7) } \\
\text { Lansoprazole (1) } \\
\text { Omeprazole (1) }\end{array}$ \\
\hline Epilepsy & $8(5.5 \%)$ & $\begin{array}{l}\text { Levetiracetam (2) } \\
\text { Acetazolamide (1) } \\
\text { Carbamazepine (1) } \\
\text { Lamotrigine (1) } \\
\text { Sodium valproate (1) } \\
\text { Stiripentol (1) } \\
\text { Topiramate (1) }\end{array}$ \\
\hline Infection & $8(5.5 \%)$ & $\begin{array}{l}\text { Trimethoprim (3) } \\
\text { Amoxicillin (1) } \\
\text { Azithromycin (1) } \\
\text { Cotrimoxazole (1) } \\
\text { Erythromycin (1) } \\
\text { Itraconazole (1) }\end{array}$ \\
\hline Constipation & $6(4.1 \%)$ & $\begin{array}{l}\text { Macrogols (5) } \\
\text { Senna (1) }\end{array}$ \\
\hline Vitamins & $6(4.1 \%)$ & $\begin{array}{l}\text { Colecalciferol (2) } \\
\text { Folic acid (2) } \\
\text { Alfacalcidol (1) } \\
\text { Ergocalciferol (1) }\end{array}$ \\
\hline Rheumatic diseases & $5(3.4 \%)$ & $\begin{array}{l}\text { Nifedipine (2) } \\
\text { Piroxicam (2) } \\
\text { Hydroxychloroquine (1) }\end{array}$ \\
\hline Immunosuppression & $4(2.8 \%)$ & $\begin{array}{l}\text { Azathioprine (2) } \\
\text { Ciclosporin (1) } \\
\text { Methotrexate (1) }\end{array}$ \\
\hline Cardiovascular & $3(2.1 \%)$ & $\begin{array}{l}\text { Atorvastatin (1) } \\
\text { Enalapril (1) } \\
\text { Losartan (1) }\end{array}$ \\
\hline Ophthalmic & $3(2.1 \%)$ & $\begin{array}{l}\text { Prednisolone (2) } \\
\text { Fluorometholone (1) }\end{array}$ \\
\hline Cholestasis & $2(1.4 \%)$ & Ursodeoxycholic acid (2) \\
\hline Emesis & $2(1.4 \%)$ & Ondansetron (2) \\
\hline Other & $6(4.1 \%)$ & $\begin{array}{l}\text { Amitriptyline (1) } \\
\text { Cholestyramine (1) } \\
\text { Dexamethasone/framycetin/ } \\
\text { gramicidin (1) } \\
\text { Levomepromazine (1) } \\
\text { Melatonin (1) } \\
\text { Propranolol (1) }\end{array}$ \\
\hline
\end{tabular}

to. I sometimes forget the folic acid as he has three days off when he's on the methotrexate. Parent of Patient 20 (methotrexate)

Eighteen $(22.5 \%)$ participants intentionally omitted doses. These were due to adverse effects $(5,27.8 \%)$, concurrent acute illness (3, 16.7\%), timing of administration (3, 16.7\%), the desire to look up more information before starting the medicines (2, 11.1\%), incorrect use (2,11.1\%), child declining to take $(1,5.6 \%)$, a mother not wanting their child to have the medicine as, although not used for this indication, they were an antidepressant $(1,5.6 \%)$ and ran out of supplies $(1,5.6 \%)$.

He was poorly once and was taking Calpol, Nurofen and antibiotics. So I stopped giving it then as I thought it was a bit much. Parent of Patient 100 (ranitidine)

Only the first night because of reading the side effects. My husband looked on the internet. Then we read the information the doctor gave us and realised it was more related to children and my husband was much happier so we gave it. Parent of Patient 56 (desmopressin)

\section{Seeking further information}

Twenty-six (30.2\%) participants sought further information about their medicine. Twenty-two participants (84.6\%) searched the internet, two $(7.7 \%)$ asked a friend/relative, one $(3.8 \%)$ asked other parents and one (3.8\%) had looked in the British National Formulary.

Participants sought further information to: find out about side effects $(13,50 \%)$, general interest $(5,19.2 \%)$, reassurance about the appropriateness of treatment $(4,15.4 \%)$, research a specific query $(3,11.5 \%)$ and check that there were no interactions with concomitant medicine(s) $(3,11.5 \%)$.

I'm giving something new. I want to know what side effects there are. [Patient 6] is on lots of medicines, she's having seizures and I want to see how it interacts with the others, I don't want to make these worse. Parent of Patient 6 (levomepromazine)

Basically, is that the right drug? Is it common to use it at this stage? Parent of Patient 75 (azathioprine)

\section{Concerns and further questions}

Twenty-four (30\%) participants who had taken/administered their medicine had some concerns. These related to side effects $(10,41.7 \%)$, efficacy $(6,25 \%)$, administration $(4,16.7 \%)$ and other concerns $(4,16.7 \%)$. Other concerns were the: perceived stigma of taking an antidepressant, impact of a friend questioning the choice of therapy, anticipated repeat prescription problems through the general practitioner (GP) and advice provided by a pharmacist.

There was one thing. My friend works in a hospital, I'm not sure what she does, but when she saw what [Patient 11] was on she said that they'd been told to stop using them. I don't know why that is. Parent of Patient 11 (piroxicam)

\section{Administration issues}

Issues regarding administration were experienced by $21(26.3 \%)$ participants. These were issues concerning: dislike of the taste/ smell $(11,52.4 \%)$, timing of administration $(3,14.3 \%)$ and the impact of autism/learning difficulties (2, 9.5\%). Other (5, $23.8 \%$ ) experiences included the: manipulation of a tablet to obtain a part-dose, problems extracting a tablet from a blister 
pack, fear of an inhaled spacer device, absence of a bottle adapter and swallowing difficulties.

It was difficult to find a suitable time as needed to be taken on an empty stomach an hour before food. She took it at school as there's no afternoon break. In the morning she has breakfast, then there's lunchtime. When she comes home she has an evening meal and then she's tired and it's time for bed. Parent of Patient 23 (lansoprazole)

He's got a new spacer now as he couldn't cope with the big one. It scared him. He's got a smaller one with bears on it now which is fine from the GP. Parent of Patient 33 (beclomethasone inhaler)

\section{Adverse effects}

While cause and effect was not established, adverse effects were reported by $29(36.3 \%)$ participants (table 3$)$.

Upper abdominal pain under her rib cage for three weeks, periodic headache, exhausted, very, very tired, her menstrual cycle has gone haywire. She's been off school for three weeks. I'm desperate to find out the cause to alleviate her symptoms. My head tells me it's the side effects from the drug... Parent of Patient 15 (ciclosporin)

I was told one of the side effects was increased appetite. But her appetite is much greater now. I didn't realise just how much it would increase. Parent of Patient 30 (pizotifen)

\section{Further supply issues}

Twelve (15\%) participants experienced difficulties obtaining further supplies. Forty-seven participants $(58.8 \%)$ had sufficient supplies from the hospital and 21 (26.3\%) obtained further supplies from their GP. The problems experienced by participants included: delays in posting out clinic letters to the GP (4, $33.3 \%)$, insufficient information on the letter for a repeat prescription $(3,25 \%)$, insufficient quantities prescribed by the GP $(2,16.7 \%)$, misreading of a letter by the GP $(1,8.3 \%)$, cancellation of a follow-up outpatient appointment where a repeat prescription was to be provided $(1,8.3 \%)$ and confusion due to a therapy substitution by the hospital pharmacy which did not then match the information in the clinic letter (1,8.3\%).

Yes, there was some confusion between the doctors. The hospital hadn't written to the GP, the letter hadn't been sent so I had to phone the consultant who organised the letter. Missed a week of the antibiotic. Parent of Patient 26 (co-trimoxazole)

Ran out of tablets. The doctor said to take the course and we'll see you back. Out-patient on 8th June cancelled by the hospital and arranged for much later in August. Had to phone up and get it brought forward. The doctor said to take it for 6 weeks. We only had a 4 week supply. Parent of Patient 45 (amitriptyline)

\section{DISCUSSION}

Patients have a right to decide not to take their medicine and may have different views about risks, benefits and side effects. ${ }^{16}$ In this current study, 6/86 (7\%) participants had not started their medicine and 18/80 (22.5\%) participants had intentionally omitted some doses. Therefore, some are reviewing the initial therapy decision and others are making treatment changes without consulting a healthcare professional. Shared decision-making between clinicians and patients about treatment choice is important. ${ }^{17}$ Poor communication may lead patients to obtain information outside of a consultation with a healthcare professional. ${ }^{18}$

Overall participant reported adherence in this study was comparable with that published in the paediatric literature. ${ }^{19}{ }^{20}$ Thirty-four (43.6\%) participants exhibited high adherence and 35 (44.9\%) medium adherence. Four (5\%) participants had purchased medicine compliance aids. Due to a lack of beneficial outcomes with the use of compliance aids the UK Royal Pharmaceutical Society recommends original pack dispensing with appropriate pharmaceutical care including clinical medication review. ${ }^{21}$

A recent systematic review identified a number of findings that contribute to explaining treatment adherence in paediatrics. ${ }^{2}$ Including beliefs about the condition or treatment, treatment

Table 3 Reported adverse effects

\begin{tabular}{|c|c|c|c|}
\hline Therapeutic use & Medicine & $\begin{array}{l}\text { Number of patients } \\
\text { reporting effect }\end{array}$ & Reported adverse effect(s) \\
\hline Eczema & $\begin{array}{l}\text { Topical corticosteroid } \\
\text { Hydroxyzine }\end{array}$ & $\begin{array}{l}1 \\
1\end{array}$ & $\begin{array}{l}\text { Staining of clothing } \\
\text { Drowsiness }\end{array}$ \\
\hline Allergy & Fluticasone & 2 & Nose bleed, sore throat \\
\hline Urinary frequency/enuresis & $\begin{array}{l}\text { Oxybutynin } \\
\text { Tolterodine }\end{array}$ & $\begin{array}{l}2 \\
2\end{array}$ & $\begin{array}{l}\text { Drowsiness, dry mouth } \\
\text { Drowsiness, dry mouth, constipation, abdominal pain }\end{array}$ \\
\hline Migraine/headache & $\begin{array}{l}\text { Pizotifen } \\
\text { Propranolol }\end{array}$ & $\begin{array}{l}3 \\
1\end{array}$ & $\begin{array}{l}\text { Behavioural changes, constipation, increased appetite } \\
\text { Fatigue }\end{array}$ \\
\hline Gastro-oesophageal reflux & Ranitidine & 1 & Vomiting \\
\hline Epilepsy & $\begin{array}{l}\text { Levetiracetam } \\
\text { Acetazolamide } \\
\text { Lamotrigine }\end{array}$ & $\begin{array}{l}2 \\
1 \\
1\end{array}$ & $\begin{array}{l}\text { Behavioural changes } \\
\text { Behavioural changes } \\
\text { Suicidal ideation }\end{array}$ \\
\hline Constipation & Macrogol & 1 & Diarrhoea \\
\hline Rheumatic diseases & $\begin{array}{l}\text { Nifedipine } \\
\text { Hydroxychloroquine }\end{array}$ & $\begin{array}{l}1 \\
1\end{array}$ & $\begin{array}{l}\text { Nausea, dizziness } \\
\text { Abdominal pain }\end{array}$ \\
\hline Immunosuppression & $\begin{array}{l}\text { Azathioprine } \\
\text { Ciclosporin } \\
\text { Methotrexate }\end{array}$ & $\begin{array}{l}2 \\
1 \\
1\end{array}$ & $\begin{array}{l}\text { Blacking out/fainting, hair loss } \\
\text { Abdominal pain, headache, fatigued, } \\
\text { changes to menstrual cycle } \\
\text { Abdominal pain }\end{array}$ \\
\hline Other & $\begin{array}{l}\text { Amitriptyline } \\
\text { Atorvastatin } \\
\text { Enalapril } \\
\text { Itraconazole } \\
\text { Propranolol }\end{array}$ & $\begin{array}{l}1 \\
1 \\
1 \\
1 \\
1\end{array}$ & $\begin{array}{l}\text { Drowsiness } \\
\text { Jaundice } \\
\text { Dry cough } \\
\text { Abdominal pain } \\
\text { Coldness of the extremities }\end{array}$ \\
\hline
\end{tabular}


regimen and child resistance. Findings from the present study were consistent with these. For example, 3/86 (3.5\%) participants decided against treatment, 21/80 (26.3\%) experienced issues with administration including the taste/smell of the medicine and timing of administration. While the systematic review ${ }^{2}$ focused on long-term conditions it did not identify when during treatment these themes occurred. This current study found that they can occur within the first 6 weeks after starting a new medicine.

A study of adult patients prescribed a new long-term medicine found that once a patient has experienced their medicine, they gain some knowledge of what it does and new questions arise. ${ }^{5}$ The current study has shown that children and their parents/ carers have similar experiences after the first few weeks of therapy. This is illustrated by $26 / 86$ (30.2\%) participants researching further information about their new medicines, 24/ $80(30 \%)$ having concerns or further questions and 29/80 (36.3\%) possibly experiencing an adverse effect to treatment.

Twenty-one (26.3\%) parents/carers had difficulties administering the medicine to their child. In adults, oral solid dosage forms are mostly acceptable. However, potential paediatric patients may include neonates, toddlers, young children and adolescents, and hence will have widely varying needs. ${ }^{22}$ A change in formulation is currently excluded from triggering an NMS consultation. $^{23}$ Any future paediatric medication review should include changes in formulation as a trigger for a medication review.

Current evidence suggests that when patients move between care providers the risk of miscommunication and unintended changes to medicines is a significant problem. ${ }^{24}$ This current study suggests that this is an issue in paediatrics with $12(15 \%)$ participants experiencing problems arranging a repeat supply with seven $(58.3 \%)$ due to a miscommunication.

A systematic review of interventions to improve the safe and effective use of medicines by consumers identified a scarcity of evidence in children/young people. ${ }^{25}$ The benefits of a medication review through the NMS have been appraised. ${ }^{7}$ The NMS appraisal identified a variety of factors impacting on adherence including forgetfulness, beliefs about treatment necessity, stigma, lack of peer/family support, lack of knowledge, side effects, fear of dependency, regimen complexity, inability to use the formulation and access to medicines. Each of these factors was identified in this current study. The NMS applies a structured approach to identifying and resolving these issues. ${ }^{723}$ However, it may not be available to children and is not available to their parents/carers. ${ }^{6}$

The results of this current study suggest that paediatric patients and their caregivers may benefit from some support initiative after the first few weeks of treatment with one option being an NMS type intervention. In addition to medication review a number of other initiatives may further support patients realising the benefits of their medicines. These include fostering better partnerships with patients, the use of telephone helplines for information on medicines, developing specific internet support websites and improvements to how different healthcare professionals collaborate together. ${ }^{13}$

The limitations of this study include sample size which was relatively small, specialist paediatric centre setting which may limit how generalisable the results are and the restriction to English language speakers.

\section{CONCLUSION}

Paediatric patients and their parents/carers experience a range of issues during the first 6 weeks after starting a new medicine. Intervention at this stage may provide useful support to both the patient and their parent/carer. Further research is required to determine the type of intervention and how it could be integrated in to practice to optimise paediatric medicine use.

\section{What this paper adds}

What is already known on this subject?

- Little is known about the experiences of paediatric patients, and their parents/carers, during the first few weeks after a child has started a new medicine.

- Adult patients have been shown to experience a number of issues following the initiation of a new medicine.

\section{What this study adds?}

- This study has shown that children, and their parents/carers, experience a range of issues during the first 6 weeks after starting a new medicine.

- These issues include concerns/questions, information requirements, adverse effects, arranging further supplies and adherence.

- Interventions to support medicine taking during this period may optimise medicines use in this group of patients.

Acknowledgements We are grateful to the support provided for the study by the staff of the Medicine Chest outpatient pharmacy at Birmingham Children's Hospital NHS Foundation Trust, UK.

Competing interests None declared.

Ethics approval The study was approved by Yorkshire and Humber-Sheffield, UK, National Research Ethics Service 24/09/14 (REC reference 14/YH/1086, IRAS project ID 148123).

Provenance and peer review Not commissioned; externally peer reviewed.

\section{REFERENCES}

1 Nieuwlaat R, Wilczynski N, Navarro T, et al. Interventions for enhancing medication adherence. Cochrane Database Syst Rev 2014;(11):CD000011.

2 Santer M, Ring N, Yardley L, et al. Treatment non-adherence in paediatric long-term medical conditions: systematic review and synthesis of qualitative studies of caregivers' views. BMC Pediatr 2014;14:63

3 Gutermann L, Decottignies A, Sharif K, et al. Parents and carers of patients who had liver transplants: opinions and experiences of medication issues. Eur J Hosp Pharm 2014;21:339-43.

4 McDonagh JE, Shaw KL, Stephenson R, et al. Are they ready and do we know they are ready? Documentation of medicine management tasks in an adolescent rheumatology clinic. Rheumatology 2014;53(Suppl 3):iii10.

5 Barber N, Parsons J, Clifford S, et al. Patient's problems with new medication for chronic conditions. Qual Saf Health Care 2004;13:172-5.

6 Prescription Services Negotiating Committee. NMS frequently asked questions. Prescription Services Negotiating Committee (cited 14 December 2015). http://psnc.org. uk/services-commissioning/advanced-services/nms/nms-frequently-asked-questions

7 Elliott RA, Boyd MJ, Waring J, et al. Understanding and Appraising the New Medicines Service in the NHS in England (029/0124). A randomised controlled trial and economic evaluation with qualitative appraisal comparing the effectiveness and cost effectiveness of the New Medicines Service in community pharmacies in England. Nottingham University, 2014.

8 Eakin MN, Bilderback A, Boyle MP, et al. Longitudinal association between medication adherence and lung health in people with cystic fibrosis. J Cyst Fibros 2011;10:258-64.

9 Koster ES, Raaijmakers JAM, Vijverberg SJH, et al. Inhaled corticosteroid adherence in paediatric patients: the PACMAN cohort study. Pharmacoepidemiol Drug Saf 2011;20:1064-72

10 So TY, Layton JB, Farrington E, et al. Cognitive pharmacy services at a pediatric nephrology and hypertension clinic. Ren Fail 2011;33:19-25.

11 Costello I, Wong ICK, Nunn AJ. A literature review to identify interventions to improve the use of medicines in children. Child Care Health Dev 2004:30:647-65.

12 National Institute for Health and Care Excellence. Medicines optimisation: the safe and effective use of medicines to enable the best possible outcomes. London: 
National Institute for Health and Care Excellence, 2015:47 (cited 11 September 2015). https://www.nice.org.uk/guidance/ng5

13 Royal College of Physicians. $N=1$, Why people matter in medicines. Recommendations of a subgroup of the Royal College of Physicians Medicines Forum. London: Royal College of Physicians, 2011 (cited 4 July 2016). https://www. rcplondon.ac.uk/file/250/download?token=EmaJnrV4

14 Birmingham Children's Hospital NHS Foundation. (Birmingham): Birmingham children's Hospital NHS Foundation Trust; (cited 14 December 2015). http://www. bch.nhs.uk/corporate/about-trust

15 Morisky DE, Ang A, Krousel-Wood M, et al. Predictive validity of a medication adherence measure in an outpatient setting. I Clin Hypertens 2008;10:348-54.

16 National Institute for Health and Care Excellence. Medicines adherence: involving patients in decisions about prescribed medicines and supporting adherence. London: National Institute for Health and Care Excellence, 2009:30 (cited 8 July 2015). https://www.nice.org.uk/guidance/cg76

17 Cribb A. Involvement, shared decision-making and medicines. London: Royal Pharmaceutical Society, 2011:60 (cited 16 December). http://www.rpharms.com/ news-story-downloads/rpsresearchreport.pdf

18 Stevenson FA, Cox K, Britten N, et al. A systematic review of the research on communication between patients and health care professionals about medicines: the consequences for concordance. Health Expect 2004;7:235-45.
19 Taddeo D, Egedy M, Frappier JY. Adherence to treatment in adolescents. J Paediatr Child Health 2008;13:19-24.

20 Dawood OT, Izham M, Ibrahim M, et al. Medication compliance among children. World J Pediatr 2010;6:200-2.

21 Royal Pharmaceutical Society. Improving patient outcomes: the better use of multi-compartment compliance aids. London: Royal Pharmaceutical Society, 2013:20 (cited 8 September 2015). http://www.rpharms.com/unsecure-support-resources/ improving-patient-outcomes-through-the-better-use-of-mcas.asp

22 Nunn T, Williams J. Formulation of medicines for children. Br J Clin Pharmacol 2005;59:674-6.

23 Prescription Services Negotiating Committee. Service specification-New Medicine Service (NMS). Prescription Services Negotiating Committee (cited 9 September 2015). http://psnc.org.uk/wp-content/uploads/2013/06/NMS-service-spec-Aug-2013changes_FINAL.pdf

24 Picton C. Keeping patients safe when they transfer between care providers-getting the medicines right. London: Royal Pharmaceutical Society, 2011:11 (cited 9 September 2015). http://www.rpharms.com/current-campaigns-pdfs/ 1303---rps---transfer-of-care-10pp-professional-guidance---final-final.pdf

25 Ryan R, Santesso N, Lowe $D$, et al. Interventions to improve safe and effective medicines use by consumers: an overview of systematic reviews. Conchrane Database Syst Rev 2014;(4):CD007768. 
CORRECTION

Correction: A telephone survey to determine the experiences of children and their parents/ carers, following the initiation of a new medicine

Aston J, Wilson KA, Sinclair A, et al. A telephone survey to determine the experiences of children and their parents/carers, following the initiation of a new medicine (Eur J Hosp Pharm 2017;24:266-71). This paper has been amended since it was published online and in print. The authors of this paper regret to advise that the Morisky Medication Adherence Scale (MMAS-8) was unintentionally used without a licence agreement from Dr Donald Morisky. As a consequence of this, reference to the use of, and results from, the MMAS- 8 has been removed from the abstract, method, results, discussion and references. These have been replaced with adherence data unrelated to the MMAS- 8 that were also collected during the study.

(C) European Association of Hospital Pharmacists (unless otherwise stated in the text of the article) 2018. All rights reserved. No commercial use is permitted unless otherwise expressly granted.

\section{D) Check for updates}

\section{(S) Linked}

- http://dx.doi.org/10.1136/ejhpharm-2016-000925

Eur J Hosp Pharm 2018;25:116.

doi:10.1136/ejhpharm-2016-000925corr1 